\title{
Factors associated with sugar-sweetened beverages consumption among Malaysian adolescents: findings from the Adolescent Nutrition Survey 2017
}

\author{
Ruhaya Salleh ${ }^{1}$, Ahmad Ali Zainuddin ${ }^{1}$, Safiah Md Yusof ${ }^{*}$, Cheong Siew Man ${ }^{1}$, \\ Mohamad Hasnan Ahmad ${ }^{1}$, Nur Shahida Abd. Aziz ${ }^{1}$, Lalitha Palaniveloo ${ }^{1}$, Azli \\ Baharudin $^{1}$ \& Norazizah Ibrahim Wong ${ }^{3}$ \\ ${ }^{1}$ Institute for Public Health, National Institutes of Health, Ministry of Health, Setia \\ Alam, 40170 Shah Alam, Selangor, Malaysia; ${ }^{2}$ International Medical University, No. \\ 126, Jalan Jalil Perkasa 19, Bukit Jalil, 57000 Kuala Lumpur, Malaysia; ${ }^{3}$ Sector of \\ Biostatistics and Data Repository, National Institutes of Health, Ministry of Health \\ Malaysia.
}

\begin{abstract}
Introduction: Childhood obesity is a public health problem in Malaysia. Intake of sugar-sweetened beverages (SSB) is associated with obesity in children. There is a lack of studies on factors associated with SSB consumption in Malaysia. This study aimed to determine the sociodemographic factors associated with SSB consumption among Malaysian adolescents. Methods: Data of 2,021 students, aged 10-17 years on sociodemographic, SSB intake and anthropometrics were drawn from the school-based Adolescent Nutrition Survey 2017. A multistage stratified cluster sampling was used to obtain a nationally representative sample of primary and secondary school students. Body mass index (BMI)-for-age status was determined based on calculated $z$-score using the World Health Organization 2007 reference. SSB consumption was obtained from a food frequency questionnaire. Results: The prevalence of overweight and obesity among Malaysian adolescents were $16.6 \%$ and $14.7 \%$, respectively. Malaysian adolescents consumed 1.4 cups of SSB per day. Rural children had a significantly higher SSB intake (1.5 cups) than urban (1.3 cups) children, while males (1.5 cups) had a significantly higher intake than females (1.3 cups). There were no significant differences in SSB consumption between thin, normal, overweight and obese adolescents. Conclusion: Almost all Malaysian adolescents consumed SSB during one month prior to the survey and the average amount consumed was 1.4 cups per day. Rural locality and male were associated with higher SSB consumption. There were differences in SSB consumption between Chinese and Malays, between Chinese and Indians, and between Chinese and Bumiputra Sarawak. There were no differences in consumption between the different BMI-for-age categories.
\end{abstract}

Keywords: Sugar-sweetened beverage, adolescent, obesity, Malaysia

\footnotetext{
*Corresponding author: Safiah Md Yusof

International Medical University, No. 126, Jalan Jalil Perkasa 19, Bukit Jalil, 57000 Kuala Lumpur, Malaysia

Tel: (6) 012-399 4998; Tel: (6) 03-2731 7067; Fax: (6) (03) 86567229

E-mail: safiah@imu.edu.my

doi: https://doi.org/10.31246/mjn-2020-0040
} 


\section{INTRODUCTION}

Childhood obesity is one of the most serious public health challenges of the 21 st century. Overweight and obese children are likely to stay obese into adulthood and more likely to develop non-communicable diseases like diabetes and cardiovascular diseases at a younger age (Juonala et al., 2011). Worldwide prevalence of overweight and obesity among children and adolescents (aged 5-19) was 18\% in 2016 (WHO, 2017). In Malaysia, the prevalence of overweight and obesity was $30.4 \%$, which affected about 1 million Malaysian adolescents (IPH, 2017). However, thinness and stunting are still prevalent among Malaysian adolescents (IPH, 2017; IPH, 2012). The problem of double burden of malnutrition faced by Malaysia is also found in low-income and middleincome countries such as China (Song et al. 2018), Mexico (Kroker-Lobos et al., 2014), and Jordan (Al-Domi et al., 2019).

Sugar-sweetened beverage (SSB) is defined as any drinks with added sugar. This includes tea, coffee, malted drinks, soft drinks, carbonated beverages, sports drinks, and fruit drinks (Luger et al., 2017). Intake of SSB has been shown to be associated with weight gain and obesity indices in children. Systematic review and meta-analysis from prospective cohort studies and randomised controlled trials concluded that SSB consumption promotes weight gain in children to adults (Malik et al., 2013), and SSB consumption is positively associated with or has effect on obesity indices in children, adolescents and adults (Luger et al., 2017). Previous studies also found that older children and adolescents were more likely to consume SSBs than younger children (Rao et al., 2015). Besides that, evidence has shown that males were more likely to consume SSBs than females (Park et al., 2012a; Park et al., 2012b; Rao et al., 2015).

The SSB consumption patterns in Asian countries vary. In a study conducted in China, it was found that $46.1 \%$ of children (6 to 13 years) regularly drank SSBs. The prevalence of obesity for regular SSB drinkers (11.6\%) and other beverages drinkers (10.1\%) was significantly $(p=0.0001)$ higher than regular milk drinkers $(7.6 \%)$. The adjusted odds ratio $(O R)(95 \% \mathrm{CI})$ for obesity was $1.46(1.21,1.75)$ in regular SSB drinkers, compared to regular milk drinkers. (Shang et al., 2012). Among Korean adolescents, Lee, Kwon \& Lee (2013) reported that the mean total SSB intake among those aged 7 to 18 years was $98.7 \mathrm{~mL} /$ day, with means of $114.1 \mathrm{~mL} /$ day for boys and $82.1 \mathrm{~mL} /$ day for girls. Being overweight and obese was significantly associated with greater ORs for high SSB intake among boys aged 7 to 12 years $(O R=1.72)$ (Lee et al., 2013). A more recent study in Korean children and adolescents 9 to 14 years old found that the mean SSB intake among boys who consumed $>200 \mathrm{~mL} /$ day was 301.7 $\mathrm{mL} /$ day and among girls, the mean was $260.9 \mathrm{~mL} /$ day (Ha et al., 2016). Boys who consumed $>200 \mathrm{~mL} /$ day had $48 \%$ lower odds of being obese (adjusted OR, $0.52 ; 95 \% \mathrm{CI}, 0.26-1.05 ; p$ for trend $=$ 0.0310) compared to boys who did not drink SSBs. No significant association was observed in girls.

In Indonesia, SSBs were consumed by $62 \%$ children and $72 \%$ adolescents. An SSB intake of one or more servings per day was observed in $24 \%$ children and $41 \%$ adolescents (Laksmi et al., 2018). The National Health Examination Survey in Thailand in 2009 reported that over $30 \%$ and $16 \%$ of adolescents aged 6-14 years and over 15 years, respectively, consumed SSBs almost every day or more often. These rates were found to be an increase of $50 \%$ and 
$100 \%$, respectively, since the previous survey in 2003 (Lim et al., 2014).

The Malaysia School-Based Nutrition Survey in 2012 reported that $24.5 \%$ of adolescents consumed sweetened tea daily and $42.2 \%$ of them consumed it weekly, with a mean intake of $397.7 \mathrm{~mL} /$ day and $564.7 \mathrm{~mL} /$ day, respectively. Chocolate drinks was the second most popular SSB with $24.0 \%$ of adolescents consuming it daily and $45.8 \%$ consuming it weekly, with a mean intake of $398.2 \mathrm{~mL} /$ day and $686.7 \mathrm{ml} /$ day, respectively (IPH, 2012). In the 2017 survey, malted drinks was the most popular SSB among the adolescents where $80.0 \%$ of them consumed it and the median intake was $99.7 \mathrm{~mL} /$ day, (IPH, 2017).

The consumption of SSB in this region is mostly higher compared to Australia where the proportion of children and youth aged 2 to 18 years who consumed SSBs on the day of the survey declined by 31\% (from 68.1\% in 1995 to $46.7 \%$ in 2011-2012) (Brand-Miller \& Barclay, 2017). Several determinants that influence children's intake of SSB have been identified. They occur at the individual, interpersonal, and environmental levels. At the individual level, it was found that SSB preference, TV viewing time, snack consumption, and frequent use of fast food restaurants were positively associated with SSB intake (Park et al., 2012a; Paes et al., 2015). At the interpersonal level, lower parental socioeconomic status, lower parental age, parental SSB consumption, parental positive attitude to soft drinks were found to influence children's SSB consumption (Paes et al., 2015). At the environmental level, school policy reduced SSB consumption, while home availability of SSB showed positive association with SSB intake (Paes et al., 2015). Other factors that were significantly associated with increased SSB intake were being male, ethnicity, and low socioeconomic status (Paes et al., 2015).

The high level of SSB consumption and the increasing trend of obesity among adolescents in this country is of increasing concern among the healthcare providers and policy makers. Studies in other countries have shown that the consumption of SSB is closely related to obesity. However, there is a lack of studies on factors such as age, sex, urban or rural locality, ethnicity and obesity associated with SSB consumption among Malaysian adolescents. Therefore, the aim of this study was to determine the factors associated with SSB consumption among Malaysian adolescents.

A unique feature of this project is that it is a national level survey with a representative sample of school children from the adolescent age group that measured SSB intake as well as weight, height and several other sociodemographic data.

\section{MATERIALS AND METHODS}

\section{Study design and sampling method}

Data on sociodemographic factors, food frequency intake and anthropometrics in this study were drawn from the Adolescent Nutrition Survey (ANS) in 2017 based on a nationally representative sample. The ANS 2017 was a school-based cross-sectional study using multistage stratified cluster sampling design to ensure the recruitment of a nationally representative sample of Standards 4 to 6 (10-12 years of age) and Forms 1 to 5 (13-17 years of age) school children. Details of the ANS 2017 methodology are described elsewhere (IPH, 2017).

Malaysia was stratified into 16 states (including the Federal Territory of Kuala Lumpur, Putrajaya, and Labuan). The first stage of sampling involved a random selection of schools from a list of eligible schools provided by the Ministry 
of Education. Schools were selected randomly with probability proportional to school enrolment size. A total of 311 schools were selected to participate in this survey. The second stage of sampling was selection of classes. Systematic random sampling was used to select classes from each selected school. All students in the selected classes were eligible to participate in the survey. The third stage of sampling was done for the purpose of administering the Habitual Food Intake module which included the food frequency questionnaire on SSB consumption. A total of 2,096 students were selected randomly from each selected class. After data cleaning, a total of 2,021 students were included in the final analysis. The inclusion criteria were Malaysians, aged 10 to 17 years old, not deaf, dumb or bed ridden, and attended school on the day of the survey.

\section{Ethics approval and consent to participate}

Ethical approvals of the study were obtained from the Medical Research Ethics Committee (MREC), Ministry of Health Malaysia (NMRR- 16-69830042) prior to conducting the study. Informed written consent was taken from all respondents and their parents / guardians at the beginning of the study.

\section{Data collection}

The ANS school-based survey was conducted from March to May 2017. Trained data collectors obtained written informed consents from the respondents and their parents/guardians before taking anthropometric measurements, and conducted a self-administered questionnaire among students using a structured, bilingual (Malay and English) questionnaire. The questionnaire included data on socio-demographic characteristics, location (urban or rural areas), sex, age, ethnicity, and school category (primary or secondary).

\section{Anthropometric measurements}

Body weight was measured using a digital weighing scale (TANITA HD 319) with an accuracy of \pm 100 gm. Subjects were weighed without shoes and in light clothing. Height was measured to the nearest $0.1 \mathrm{~cm}$ using a stadiometer (SECA 213). Weight and height measurements were done using standard procedures (Lee \& Nieman, 2010). Z-score for body mass index (BMI)-for-age was calculated using the World Health Organization (WHO) AnthroPlus software (WHO, 2009) based on WHO growth reference for school-aged children and adolescents (WHO, 2007).

\section{Dietary intake}

Assessment of SSB

Dietary information was collected by trained nutritionists using a semiquantitative food frequency questionnaire (FFQ) which consisted of 136 commonly consumed food items in Malaysia. It took 30-45 minutes to complete depending on the literacy of the respondents. The same FFQ had been pre-tested and used in the Malaysia School-Based Nutrition Survey in 2012 (IPH, 2012), but it has not been tested for its validity and reliability. This FFQ aimed to describe the habitual food intake among adolescents studying in Primary 4 to Secondary 5 in Malaysian schools. The FFQ was integrated into the Survey Creating System (SCS), which is an automated data collection system (installed in a tablet) to ensure more effective data collection and data processing work.

The FFQ was used to evaluate the habitual intake of SSB. Following is the list of SSBs included in the questionnaire - fruit drinks, regular carbonated flavoured drinks, isotonic drinks, soft drink bases, syrups, botanical beverage mixes, soybean milk/drinks, cow's milk, cultured milk, sweetened tea, instant coffee, and malted drinks, in accordance with the Malaysian Food Regulation 
(1985) and the Malaysian Adults Nutrition Survey 2014 (IPH, 2014). The amount of SSB consumption per day was based on household measurement $(1$ glass $=250 \mathrm{~mL}, 1$ can $=325 \mathrm{~mL}$, and 1 bottle $=500 \mathrm{~mL}$ ).

Adolescents were asked to recall the frequency and amount of any types of SSB drinks that they usually consume during one month prior to the interview. The question asked was "How often (times either per day or per week or per month) did you drink the following types of beverages during the past one month? If yes, how many servings did you take each time?". Respondents should choose only one option - either times per day or per week or per month. Dietary assessment aids such as household measurement tools and the Malaysian Food Album (IPH, 2011) were used to facilitate the respondents in quantifying the portion size of the foods and beverages consumed.

\section{Data analysis}

Data analysis was done using IBM SPSS version 21. Complex samples analysis procedures were used in the analysis and was carried out at 95\% confidence interval. The WHO Anthroplus software was used to enter and determine the BMI-for-age status for the respondents. Weight, height, and age data were used to calculate BMI-for-age $z$-score and categorise subjects into thinness, normal, overweight, and obese based on the WHO growth reference (WHO, 2017). Thinness was defined as low BMIfor-age at $<-2$ standard deviation (SD), overweight at $>+1 \mathrm{SD}$ to $\leq+2 \mathrm{SD}$, and obese at $>+2$ SD.

All the different types of SSB were recategorised into a new variable called SSB. The amount of any drinks taken was recorded either in cups or glasses and all measurements were converted into millilitres $(\mathrm{mL})$. All frequency of intakes were converted into number of times SSB was taken per day. If the respondent answered in the per week column, the frequency was divided by seven days (frequency per week/7); if the respondent answered in the per month column, the frequency was divided by 30 days (frequency per month/30). The total amount of SSB taken was calculated by multiplying the frequency of intake (now all converted into per day) with the amount taken each time. Volume $(\mathrm{mL} /$ day $)=(n$ of days $\mathrm{x}$ total amount of beverages consumed)/ 7 days. Data were presented as median $\left(25^{\text {th }}\right.$ percentile; $75^{\text {th }}$ percentile) as none had a normal distribution.

Mann-Whitney and Kruskal-Wallis tests were used in this paper because the data were not normally distributed. Mann-Whitney U test was used to assess if there were any differences in consumption between urban and rural, between male and female, and between primary and secondary school adolescents. Kruskal-Wallis test was used to assess if there were any differences in consumption between the ethnic groups and BMI-for-age groups. Kruskal-Wallis post-hoc test was done to determine which of the ethnic groups and which of the BMI-for-age groups had significant differences in SSB consumption.

\section{RESULTS}

\section{Socio-demographic characteristics}

A total of 2,096 school children were eligible for this study, and 2,021 completed the food frequency questionnaire on food intake. However, 2,017 had complete data on SSB intake to be analysed. Table 1 shows the distribution according to sociodemographic characteristics. Almost $55 \%$ of the subjects were from the urban area, and there were similar proportion of males and females. Malays comprised the largest proportion in this survey $(65.1 \%)$, followed by Chinese 
(17.0\%) and Indians (4.0\%). Sixty-eight percent of subjects were in secondary schools.

\section{Intake of SSB}

Overall, the prevalence for intake of any SSB during the one-month period before the survey was $98.2 \%$ (95\% CI 97.4 98.8). Table 2 shows the SSB intake by sociodemographic status and BMI-forage categories. The median SSB intake for overall adolescent population was $345.1 \mathrm{~mL} /$ day $(95 \%$ CI 187.2 - 545.3), which was about 1.4 cups $(250 \mathrm{~mL} /$ cup). The highest intake of SSB was found among Bumiputra Sarawak at $455.1 \mathrm{~mL} /$ day (95\% CI 261.3 - 737.1), which was about 1.8 cups. The second highest was among Indian adolescents at $382.8 \mathrm{~mL} /$ day (95\% CI $225.4-553.6)$, which was about 1.5 cups. Chinese adolescents had the lowest intake of SSB at $276.4 \mathrm{~mL} /$ day (95\% CI 127.9 448.5). In the BMI-for-age categories, overweight adolescents had the highest SSB consumption $(371 \mathrm{~mL} /$ day $(95 \% \mathrm{CI}$ $205.9-534.0)$.

\section{Factors associated with SSB consumption}

Rural children had a significantly higher SSB consumption compared to urban children $(p=0.01)$, while males had a significantly higher intake than females $(p<0.01)$. There was no difference in SSB consumption between primary (younger) and secondary school (older) adolescents. After post-hoc tests, there were significant differences in SSB consumption between Chinese and

Table 1. Sociodemographic characteristics of subjects $(n=2,021)$

\begin{tabular}{lll}
\hline Characteristics & $n$ & $\%$ \\
\hline Location & 1106 & 54.7 \\
$\quad$ Urban & 915 & 45.3 \\
Rural & & \\
Sex & 1011 & 50.0 \\
Male & 1010 & 50.0 \\
Female & & \\
Ethnicity & 1315 & 65.1 \\
Malay & 344 & 17.0 \\
Chinese & 80 & 4.0 \\
Indian & 142 & 7.0 \\
Bumiputra Sabah & 94 & 4.7 \\
Bumiputra Sarawak & 46 & 2.3 \\
Others & & \\
School category & 647 & 32.0 \\
Primary & 1374 & 68.0 \\
Secondary & & \\
SSB consumption on a daily basis & 916 & 96.4 \\
Yes & 34 & 3.6 \\
No & & \\
SSB consumption on a weekly basis & 1735 & 99.9 \\
Yes & 1 & 0.1 \\
No & & \\
SSB consumption on a monthly basis & 1993 & 98.7 \\
Yes & 26 & 1.3 \\
No & &
\end{tabular}


Malays $(p<0.01)$, between Chinese and Indians $(p<0.01)$, and between Chinese and Bumiputra Sarawak adolescents $(p<0.01)$, as shown in Table 3. There were no significant differences in SSB consumption between thin, normal, overweight, and obese adolescents (Table 2).

\section{DISCUSSION}

Our survey showed that almost all (98.0\%) Malaysian adolescents nationwide consumed some types of SSB.
The average taken among consumers was about 1.4 cups/day. However, there were no differences in SSB intake between different BMI-for-age status. Other studies have found that lack of physical activity, poor dietary habits, and low quality diet such as high energydense foods and SSBs, which are low in micronutrients, contribute to excess body weight in adolescents (KrokerLobos et al., 2014; Al-Domi et al., 2019). Our adolescents had low physical activity level as reported elsewhere (IPH, 2017).

Table 2. Factors associated with SSB consumption among Malaysian adolescents $(n=1,993)$

\begin{tabular}{|c|c|c|c|c|c|c|c|}
\hline \multirow{2}{*}{$\begin{array}{c}\text { Socio- } \\
\text { demography }\end{array}$} & \multirow{2}{*}{$n$} & \multirow{2}{*}{$\begin{array}{l}\text { Estimated } \\
\text { population }\end{array}$} & \multirow{2}{*}{$\begin{array}{l}\text { Median } \\
\text { (mL/day) }\end{array}$} & \multicolumn{2}{|c|}{$\begin{array}{c}\text { 95\% Confidence } \\
\text { Interval }\end{array}$} & \multirow{2}{*}{$\begin{array}{l}x^{2}(d f) \text { or } z^{*} \\
\text { stats }\end{array}$} & \multirow{2}{*}{$p$ value } \\
\hline & & & & $\begin{array}{c}25 \text { th } \\
\text { percentile }\end{array}$ & $\begin{array}{c}75 \text { th } \\
\text { percentile }\end{array}$ & & \\
\hline OVERALL & 1993 & $3,430,696$ & 345.1 & 187.2 & 545.3 & & \\
\hline \multicolumn{8}{|l|}{ Location ${ }^{+}$} \\
\hline Urban & 1092 & $1,924,426$ & 326.6 & 180.2 & 519.6 & -2.46 & 0.01 \\
\hline Rural & 901 & $1,506,271$ & 364.2 & 199.5 & 612.7 & & \\
\hline \multicolumn{8}{|l|}{$\operatorname{Sex}^{\dagger}$} \\
\hline Male & 996 & $1,718,174$ & 370.2 & 211.8 & 593.5 & -5.07 & $<0.00$ \\
\hline Female & 997 & $1,712,522$ & 312.8 & 165.8 & 508.6 & & \\
\hline \multicolumn{8}{|l|}{ Ethnicity } \\
\hline Malay & 1305 & $2,221,678$ & 348.1 & 199.3 & 572.2 & $48.74(5)$ & $<0.01$ \\
\hline Chinese & 333 & 612,394 & 276.4 & 127.9 & 448.5 & & \\
\hline Indian & 80 & 156,360 & 382.8 & 225.4 & 553.6 & & \\
\hline $\begin{array}{l}\text { Bumiputera } \\
\text { Sabah }\end{array}$ & 138 & 191,663 & 350.0 & 206.7 & 601.0 & & \\
\hline $\begin{array}{l}\text { Bumiputera } \\
\text { Sarawak }\end{array}$ & 93 & 167,987 & 455.1 & 261.3 & 737.1 & & \\
\hline Others & 44 & 80,614 & 279.6 & 154.9 & 692.4 & & \\
\hline \multicolumn{8}{|l|}{ School category ${ }^{\dagger}$} \\
\hline Primary & 635 & $1,313,502$ & 345.9 & 191.2 & 550.0 & -0.66 & 0.51 \\
\hline Secondary & 1358 & $2,117,194$ & 343.1 & 184.5 & 542.4 & & \\
\hline \multicolumn{8}{|l|}{ BMI categories } \\
\hline Thinness & 111 & 204,076 & 348.8 & 207.5 & 578.6 & $3.55(3)$ & 0.31 \\
\hline Normal & 1277 & $2,150,939$ & 337.4 & 188.6 & 535.7 & & \\
\hline Overweight & 316 & 570,961 & 371.8 & 205.9 & 534.0 & & \\
\hline Obese & 285 & 502,372 & 330.4 & 156.9 & 609.5 & & \\
\hline
\end{tabular}

†Mann-Whitney U test

${ }^{\ddagger}$ Kruskal-Wallis test 
Table 3. Differences in SSB intake between ethnicities among Malaysian adolescents

\begin{tabular}{lccccc}
\hline Sample1-Sample2 & $\begin{array}{c}\text { Test } \\
\text { Statistic }\end{array}$ & Std. Error & $\begin{array}{c}\text { Std. test } \\
\text { statistic }\end{array}$ & Sig & Adj. Sig. \\
\hline Chinese-Bumiputera Sabah & -164.82 & 58.26 & -2.83 & 0.01 & 0.07 \\
Chinese-Others & -165.95 & 92.31 & -1.79 & 0.07 & 1.00 \\
Chinese-Malays & 217.89 & 35.33 & 6.17 & $<0.00$ & $<0.00^{*}$ \\
Chinese-Indian & -254.89 & 71.65 & -3.56 & 0.00 & $0.01^{*}$ \\
Chinese-Bumiputera Sarawak & -360.58 & 67.49 & -5.34 & 0.00 & $0.00^{*}$ \\
Bumiputera Sabah-Others & -1.14 & 99.63 & -0.01 & 0.99 & 1.00 \\
Bumiputera Sabah-Malays & 53.07 & 51.51 & 1.03 & 0.30 & 1.00 \\
Bumiputera Sabah-Indian & 90.08 & 80.87 & 1.11 & 0.27 & 1.00 \\
Bumiputera Sabah-Bumiputera & -195.77 & 77.21 & -2.54 & 0.01 & 0.17 \\
Sarawak & 51.94 & 88.21 & 0.59 & 0.56 & 1.00 \\
Others-Malays & 88.95 & 108.01 & 0.82 & 0.41 & 1.00 \\
Others-Indian & 194.63 & 105.29 & 1.85 & 0.07 & 0.97 \\
Others-Bumiputera Sarawak & -37.01 & 66.28 & -0.56 & 0.58 & 1.00 \\
Malays-Indian & -142.70 & 61.76 & -2.31 & 0.02 & 0.31 \\
Malays-Bumiputera Sarawak & -105.69 & 87.75 & -1.20 & 0.23 & 1.00 \\
Indian-Bumiputera Sarawak & & & & &
\end{tabular}

Notes:

1. Each node shows the sample average rank of Ethnicity

2. Each row tests the null hypothesis that the Sample 1 and Sample 2 distributions are the same

3. Asymptotic significances (2-sided tests) are displayed

4. Significant values have been adjusted by the Bonferroni correction for multiple test ${ }^{*} p<0.05$

Many studies have shown an association between SSB intake and overweight/obesity (Malik et al., 2013; Luger et al., 2017). The lack of association between SSB and BMI-forage $z$-score in our study could be due to several reasons. In this study, we did not adjust for under- or over-reporting, and as most children had high intakes of SSB, no association could be detected (Hasnain et al. 2014). Aside from that, obese children could have reduced their SSB intake in order to lose weight (Park et al., 2012b), which would further weaken the association expected.

Studies have shown that SSBs contribute between $10 \%$ to $15 \%$ of youth's caloric intake and are the primary source of added sugar in the diet of children and adolescents (Hu \& Malik, 2010). In a national survey among Malaysian adolescents, it was found that obese adolescents had the highest energy intake $(2,232 \mathrm{kcal} /$ day $)$ and the highest fat intake $(88.75 \mathrm{~g} /$ day), whereas thin adolescents had the lowest at $1,853 \mathrm{kcal} /$ day and $60.58 \mathrm{~g} /$ day, respectively (IPH, 2017). The energy intake of these obese adolescents was $107.64 \%$ above the Malaysian recommended nutrient intake $(\mathrm{MOH}$ Malaysia, 2017) and their fat intake was $105.42 \%$ of the Recommended Nutrients Intake (RNI). Overweight and obese children had a high intake of added sugar, which were $34.50 \mathrm{~g} /$ day and 
$58.31 \mathrm{~g} /$ day, respectively. Other sources of added sugar besides SSB include confectionaries and snacks. Thus, in that study, obese children may have had an excess calorie not only from SSBs, but also from confectionaries, snacks, as well as fat. This could be the reason why we could not detect any significant association between SSB consumption and BMI-for-age status among our subjects.

As stated earlier, the strength of this study was its large nationwide representative sample, which allowed for its reliable inference to Malaysian adolescents in general within the same age group. For nutritional assessment, we applied a semi-quantitative FFQ that has demonstrated to be a practical and affordable technique, thus widely used to measure nutrient intakes in epidemiological studies. One of the limitations of this study was the lack of data on physical activity levels, which could have affected SSB intake and weight status. FFQ has been found to underestimate the frequency of beverages consumed and overestimate the quantity of beverages consumed (Cock et al., 2016). Furthermore, the FFQ used in this study has not been tested for its validity and its reliability. Thus, we acknowledge that the assessment of SSB intake may have had measurement errors such as misclassification of subjects that could lead to bias in the results. Nevertheless, $\mathrm{Hu}$ (2008) commented that using food frequency questionnaire reflects longer-term dietary habits, although quantitatively imprecise.

\section{CONCLUSION}

Nearly all Malaysian adolescents reported that they had consumed SSB during the last one month and the average amount consumed was 1.4 cups/day. Our study indicated that locality, sex, and ethnicity contributed to differences in SSB consumption among adolescents. BMI-for-age status did not show any association with SSB consumption. This could be due to other factors such as excess energy intake from fat, other sources of sugar, and low energy expenditure from physical activity.

\section{Acknowledgment}

The authors would like to thank the Director General of Health Malaysia for permission to publish this paper. Appreciation goes to the Department of Statistics, Malaysia in the sampling process. Acknowledgement also goes to Ministry of Health Malaysia, namely Nutrition Division, State Health Departments, Liaison Officers and scouts in the preparation of and during data collection. Our sincere appreciation also goes to all data collectors and participants. The author(s) disclosed receipt of the following financial support for the research, authorship, and/or publication of this article: Research was funded by the Ministry of Health Malaysia.

\section{Availability of data and materials}

The dataset of this article belongs to the ANS project. At present, the data are not publicly available but can be obtained from the authors upon reasonable request and with the permission from the Director General of Health, Malaysia.

\section{Authors' contributions}

RS, principal investigator, conceptualised, drafted and reviewed the manuscript; AAZ, assisted in drafting of the manuscript, data analysis, reviewed the manuscript; SMY, prepared the draft of the manuscript and reviewed the manuscript; CSM, MHA, NSAA, LP, AB, assisted in drafting of the manuscript, reviewed the manuscript, conducted data collection; NIW conducted data analysis and interpretation, and reviewed the manuscript.

\section{Conflict of interest}

The author(s) declare no potential conflicts of interest with respect to the research, authorship, and/or publication of this article.

\section{References}

Al-Domi HA, Faqih A, Jaradat Z, Al-Dalaeen A, Jaradat S \& Amarneh B (2019). Physical activity, sedentary behaviors and dietary patterns as risk factors of obesity among Jordanian schoolchildren. Diabetes Metab Syndr: Clin Res Rev 13(1):189-194. 
Berry C, Burton S \& Howlett E (2017). Double Trouble: Commingled Effects of Fast Food and Sugar-Sweetened Beverage Consumption and the Intervening Role of Physical Activity on Childhood Obesity. Atlantic Marketing Journal 6(2):55-65.

Brand-Miller JC \& Barclay AW (2017). Declining consumption of added sugars and sugarsweetened beverages in Australia: a challenge for obesity prevention. Am J Clin Nutr 105:85463.

De Cock N, Van Camp J, Kolsteren P, Lachat C, Huybregts L, Maes L, ... \& Eggermont S (2017). Development and validation of a quantitative snack and beverage food frequency questionnaire for adolescents. J Hum Nutr Diet 30(2):141-150.

Gan WY, Mohamed SF \& Law LS (2019). Unhealthy Lifestyle Associated with higher Intake of Sugar-Sweetened Beverages among Malaysian School-Aged Adolescents. Int $J$ Environ Res Public Health 16(15):2785.

Ha K, Chung S, Lee HS, Kim C, Joung H, Paik HY \& Song YJ (2016). Association of Dietary Sugars and Sugar-Sweetened Beverage Intake with Obesity in Korean Children and Adolescents. Nutrients 8:31. doi:10.3390/nu8010031

Hasnain SR, Singer MR, Bradlee ML \& Moore LL (2014). Beverage intake in early childhood and change in body fat from preschool to adolescence. Child Obes 10(1):42-49.

Hu F (2008). Dietary assessment methods. In: Hu F (Ed). Obesity epidemiology (pp. 84-118). Oxford University Press, Oxford.

Hu FB \& Malik VS (2010). Sugar-sweetened beverages and risk of obesity and type 2 diabetes: Epidemiologic evidence. Physiol Behav 100:47-54.

IPH (2011). Malaysian Food Album 2011. Institute for Public Health, Ministry of Health Malaysia, Kuala Lumpur.

IPH (2012). Malaysia School-Based Nutrition Survey 2012. Institute for Public Health, Ministry of Health Malaysia, Kuala Lumpur.

IPH (2014). Malaysian Adult Nutrition Survey 2014. Institute for Public Health, Ministry of Health Malaysia, Kuala Lumpur.

IPH (2017). The National health and Morbidity Survey (NHMS), The National Adolescent Nutrition Survey 2017. Institute for Public Health, Ministry of Health Malaysia, Kuala Lumpur.
Juonala M, Juhola J, Magnussen CG, Wurtz P, Viikari JSA, Thomson R, Seppala I, Hernesniemi J, Kahonen M, Lehtimaki T, Hurme M, Telama R, Mikkils V, Eklund c, Rasanen L, Hintsanen M, Jarvinen LK, Kivimaki M \& Raitakari OT (2011). Childhood environmental and genetic predictors of adulthood obesity: The Cardiovascular Risk in Young Finns Study. $J$ Clin Endocrinol Metab 96:1542-1549.

Kroker-Lobos MF, Pedroza-Tobías A, Pedraza LS \& Rivera JA (2014). The double burden of undernutrition and excess body weight in Mexico. Am J Clin Nutr 100:1652S-8S.

Laksmi PW, Morin C, Gandy J, Moreno LA, Kavouras, SA, Martinez H, Salas-Salvadó J \& Guelinckx I (2018). Fluid intake of children, adolescents and adults in Indonesia: results of the 2016 Liq.In national cross-sectional survey. Eur J Nutr 57 (Supp 13):S89-S100. https:/ / doi. org/10.1007/s00394-018-1740-z

Lee RD \& Nieman DC (2010). Nutritional assessment ( $5^{\text {th }}$ Edition). McGraw-Hill Education, New York.

Lee HS, Kwon SO \& Lee Y (2013). Weight Status and Dietary Factors Associated with SugarSweetened Beverage Intake among Korean Children and Adolescents - Korea National Health and Nutrition Examination Survey, 2008-2011. Clin Nutr Res 2:135-142. http:// dx.doi.org/10.7762/cnr.2013.2.2.135.

Lim L, Banwell C, Bain C, Banks E, Seubsman S-A, Kelly M, Yiengprugsawan V \& Sleigh A (2014). Sugar Sweetened Beverages and Weight Gain over 4 Years in a Thai National Cohort A Prospective Analysis. PLoS ONE 9(5):e95309. doi:10.1371/journal.pone.0095309.

Luger M, Lafontan M, Maira Bes-Rastrollo M, Winzer E, Yumuk V \& Farpour-Lambert N (2017). Sugar-Sweetened Beverages and Weight Gain in Children and Adults: A Systematic Review from 2013 to 2015 and a Comparison with Previous Studies. Obes Facts 10:674-693

Malaysia Food Regulation (1985). Malaysian law on food and drugs. Malaysian Law Publishers.

Malik VS, Pan A, Willett WC \& Hu FB (2013). Sugar-sweetened beverages and weight gain in children and adults: a systematic review and meta-analysis. Am J Clin Nutr 98:1084-102.

Paes M, Hesketh K, O’Malley C, Moore H, Summerbell C, Griffin S, van Sluijs EMF, Ong KK \& Lakshman R (2015). Determinants of sugar-sweetened beverage consumption in young children: a systematic review. Obes Rev 16:903-913. doi: 10.1111/obr.12310. 
Park S, Sherry B, Foti K \& Blanck HM (2012a). Selfreported academic grades and other correlates of sugar-sweetened soda intake among US adolescents. J Acad Nutr Diet 112(1):125-131.

Park S, Blanck HM, Sherry B, Brener N \& O'Toole $\mathrm{T}$ (2012b). Factors associated with sugarsweetened beverage intake among United States high school students. J Nutr 142(2):306312 .

Rao G, Kirley K, Weiss-Coleman R, Inman JJ, Bauer V, Zhou Y \& Hledin V (2015). Consumption patterns of sugar-sweetened carbonated beverages among children and adolescents. Curr Cardiovasc Risk Rep 9(1):1-19.

Shang XW, Liu AL, Zhang Q, Hu XQ, Du SM, Ma J, Xu GF, Li Y, Guo HW, Du L, Li TY \& Ma GS (2012). Report on Childhood Obesity in China (9): Sugar-sweetened Beverages Consumption and Obesity. Biomed Environ Sci 25(2):125-132

Song Y, Agardh A, Ma J, Li L, Lei Y, Stafford RS \& Proschaska JJ (2018). National Trends in stunting, thinness and overweight among Chinese school-aged children, 1985-2014. Int J Obes 43:402-411.
WHO (2007). Growth reference 5-19 years. World Health Organization, Geneva. From https:// www.who.int/growthref/en/ [Retrieved August 21, 2020].

WHO (2009). WHO AnthroPlus for Personal Computers Manual: Software for assessing growth of the world's children and adolescents. World Health Organization, Geneva. From https://www.who.int/growthref/tools/who_ anthroplus_manual.pdf [Retrieved July 11, 2020]

WHO (2017). Global Health Observatory (GHO) data: Prevalence of overweight among adolescents and children. World Health Organization, Geneva. From https://www.who.int/gho/ncd/ risk_factors / overweight_obesity/overweight_ adolescents/en/ [Retrieved September 13, 2020] 